\title{
A GENIALIDADE PROJETUAL DE BORNANCINI E PETZOLD EM DESIGN GRÁFICO
}

Gustavo Cossio, MSc

Instituto Federal de Santa Catarina - IFSC

dsgcossio@gmail.com

Resumo: Em uma perspectiva histórica, a investigação trata sobre projetos desenvolvidos por uma parceria pioneira em design no sul do Brasil. A partir do reconhecimento por um trabalho marcado pela inovação de produtos e processos, o objetivo é acrescentar que José Carlos Mário Bornancini e Nelson Ivan Petzold contribuíram para a inserção de uma cultura de design gráfico em âmbito regional. A dupla de designers desenvolveu identidades visuais, embalagens e catálogos para uma série de organizações, especialmente as indústrias para as quais projetavam produtos. Uma vez que a linguagem visual se reporta às prerrogativas estéticas do modernismo, a fundamentação teórica aborda um breve panorama sobre a sua influência no design. A metodologia empregada consiste na história oral, com o testemunho pessoal de Petzold, em entrevistas com o designer. Compreende-se que, assim como em design de produto, a análise sobre o portfolio de design gráfico de Bornancini e Petzold indica fatores relevantes para contribuição no ensino e no desenvolvimento de projeto.

Palavras-chave: história do design, design gráfico, modernismo.

Abstract: In a historical perspective the investigation is about projects developed by a pioneer partnership in design in southern Brazil. From the recognition for a work with the innovation of products and processes as a key point, the goal is to add that Jose Carlos Mario Bornancini and Nelson Ivan Petzold contributed for the insertion of a graphic design culture in the regional level. The duo of designers developed visual identities, packaging and catalogs for a number of organizations, especially the industries for which they would design products. Once the visual language refers to the aesthetic prerogatives of modernism, the theoretical basis approaches a brief overview of its influence in design. The methodology consists of oral history, with the personal testimony of Petzold, in interviews with the designer. It is understood that, as well as in industrial design, the analysis of Bornancini and Petzold's graphic design portfolio indicates relevant factors for contribution in teaching and project development.

Keywords: design history, graphic design, modernism. 


\section{INTRODUÇÃO}

Este artigo apresenta um estudo sobre os projetos gráficos desenvolvidos por uma parceria em design, reconhecida nacionalmente como referência em projeto de produto. Com atuação a partir do estado do Rio Grande do Sul, José Carlos Mário Bornancini (Caxias do Sul, 1923 - Porto Alegre, 2008) e Nelson Ivan Petzold (Porto Alegre, 1931) desenvolveram produtos para diversos setores da indústria, desde utensílios domésticos a máquinas agrícolas ${ }^{1}$. Destaca-se que o sucesso dos designers perpassa cinco décadas, dos anos 1960 aos 2000, com um trabalho que tem como palavra-chave a inovação (CARDOSO, 2008; CURTIS; HENNEMANN, 2006; ELLWANGER; LIMA, 2008; LEON, 2005).

Embora encontre-se pesquisas sobre seu portfolio e casos de inovação pelo design de produto, a análise da produção de Bornancini e Petzold em design gráfico se justifica pelo seu caráter inédito. Logo, espera-se oportunizar uma reflexão sobre o papel da dupla de designers para uma cultura de projeto no sul do país, como modo de contribuir para o estudo da história do design no Brasil.

Este trabalho integra uma pesquisa sobre a história da atividade em âmbito regional, na qual são privilegiados os atores sociais que contribuem para a consolidação de uma cultura de design local, do período de industrialização ao cenário contemporâneo. Os resultados são publicados sistematicamente no Congresso Brasileiro de Pesquisa e Desenvolvimento em Design - P\&D Design e na Revista Estudos em Design².

O estudo estabelece nexos entre a linguagem visual dos projetos desenvolvidos por Bornancini e Petzold e as prerrogativas estéticas do modernismo. Portanto, é traçado um breve panorama sobre o tema, com base em uma revisão de literatura. 0 quadro teórico é composto por historiadores do design, com ênfase no aporte de Lucy Niemeyer (2007), Pedro Luiz Pereira de Souza (2008) e Rafael Cardoso (2008), docentes da Escola Superior de Desenho Industrial da Universidade Estadual do Rio de Janeiro - ESDI/UERJ.

Para o levantamento sobre os projetos gráficos, empregou-se o método da história oral, que consiste na realização de entrevistas com pessoas que fizeram parte, presenciaram os acontecimentos ou participaram da conjuntura (ALBERTI, 2007). Assim, a análise é realizada a partir do olhar privilegiado de Nelson Ivan Petzold, com depoimentos registrados em áudio e posteriormente transcritos ${ }^{3}$. Além disso, a pesquisa iconográfica e documental é feita com uma consulta ao arquivo pessoal do designer.

\section{DESENVOLVIMENTO}

A fundamentação teórica busca compreender as repercussões do modernismo no design, com o propósito de contextualizar os trabalhos de Bornancini e Petzold. Em seguida, são analisados os seus projetos gráficos para diversas instituições.

\footnotetext{
${ }^{1}$ Os futuros colegas conheceram-se quando Petzold prestou vestibular e perdeu a vaga. Inconformado, questionou a banca examinadora, e o então professor Bornancini reconheceu o equívoco. Ambos atuaram no ensino, como docentes dos cursos de Arquitetura e Engenharia da Universidade Federal do Rio Grande do Sul - UFRGS. Em 2012, Petzold recebeu o título de Professor Emérito da UFRGS.

2 Além de Bornancini e Petzold, estudos anteriores trataram das trajetórias de Norberto Bozzetti, Antônio Endler, Manlio Gobbi e os escritórios Verdi Design e Bertussi Design.

${ }^{3}$ A entrevista foi realizada em abril de 2016, na residência de Nelson Ivan Petzold, em Porto Alegre - RS.
} 


\subsection{Por uma utopia social: as influências do modernismo no design}

Durante o período do alto modernismo, entre as décadas de 1920 e 1960, a tendência predominante no design e na arquitetura foi chamada de Estilo Internacional. De acordo com Cardoso (2008), seu postulado era que todo objeto poderia ser reduzido e simplificado, até atingir uma forma que seria o reflexo estrutural e construtivo perfeito da função. Souza (2008, p. 22) corrobora o conceito: "a ideologia do progresso juntamente com o desenvolvimento técnico e científico, conduziu à ideia de que a beleza de um objeto depende de sua utilidade e eficiência", sendo essa a definição clássica do funcionalismo em design ${ }^{4}$. Salienta-se que a constituição do campo de atuação profissional tem como raiz o funcionalismo, que estabeleceu uma série de parâmetros para garantir a execução de um bom design. Em consonância, a noção da práxis profissional transparente - invisível - vincula-se diretamente aos projetos que seguem a máxima a forma segue a função, marcante na modernidade (GRUSZYNSKI, 2008).

Considerada um paradigma do ensino do design, a Bauhaus evoluiu na Alemanha durante o período pós-Primeira Guerra Mundial. A produção originária desta escola caracterizou-se pela configuração prático-funcional, cuja aparência visual fundamentou-se em uma teoria estética elementar ${ }^{5}$. Durante a fase de Dessau (19251932), a Bauhaus articulou as condições sociais, políticas e tecnológicas necessárias para atingir uma nova síntese: a simplificação e a padronização. Através da exploração de dois fatores inerentes à cultura industrial, a produção de menor custo econômico e uma estética própria, foi possível obter o design de configuração formal simples, isento de ornamentos, típico da produção serial do século XX. No ensino da comunicação visual, as formas eram acreditadas como puras, claras e despojadas ${ }^{6}$ (CARDOSO, 2008; CURTIS, 2010; KOPP, 2009; LUPTON; MILLER, 2009; SOUZA, 2008).

Por sua vez, Niemeyer (2007) assevera que a doutrina estética racionalista se estruturava em dois eixos fundamentais: uma utopia social e um vocabulário plástico cujas sintaxes buscavam sua lógica naquele princípio de harmonia universal, em uma unidade por trás da diversidade das coisas e uma semelhança entre tudo que existe apesar de suas formas, na analogia entre o micro e o macro. A ideologia do Estilo Internacional se baseava na ideia de que a criação de formas universais reduziria as desigualdades e promoveria uma sociedade mais justa?.

Ao abordar os reflexos do Estilo Internacional no design gráfico, Cardoso (2008) menciona a sua manifestação através da austeridade, do rigor e da precisão associadas à chamada 'escola suíça', termo um tanto genérico utilizado para se referir aos trabalhos realizados por designers como Jan Tschichold, Ernst Keller, Max Bill, Adrian

\footnotetext{
${ }^{4}$ As primeiras manifestações do protofuncionalismo tem origem ainda no início do século XIX, na Inglaterra e na Alemanha, ao passo do surgimento de conceitos importantes para a modernidade, tais como indivíduo, cidadania, progresso e industrialização (SOUZA, 2008).

5 Atenta às manifestações culturais, a Bauhaus empregou elementos do desenho provenientes de movimentos artísticos modernistas como o Cubismo, o Construtivismo, e o De Stjil, os quais abstraíram os elementos visuais a figuras geométricas como o quadrado, o círculo e o triângulo equilátero, e às cores primárias, amarelo, azul e vermelho (LUPTON; MILLER, 2009; SOUZA, 2008).

${ }^{6}$ A Bauhaus (1919-1933) e a Escola de Ulm (1953-1968) compartilhavam do mesmo ideário, concebendo o design como uma influência reformadora da sociedade. No entanto, o modelo ulminiano incorpora o avanço científico e tecnológico, em novas disciplinas com ênfase em ergonomia, métodos qualitativos e quantitativos, além do rigor metodológico (CARDOSO, 2008; SOUZA, 2008; STOLARSKI, 2008).

${ }^{7} \mathrm{~A}$ ironia histórica com relação ao Estilo Internacional está no fato de ter sido adotado como estilo comunicacional e arquitetônico das grandes corporações internacionais (CARDOSO, 2008; KOPP, 2009).
} 
Frütiger, Emil Ruder, Armin Hofmann e Joseph Muller-Brockmann, que impuseram definitivamente o grid como parâmetro construtivo. Além disso, o rigor característico da influência do modernismo no design gráfico se revela pela abstração formal e a geometria euclidiana, a ordem matemática e a racionalidade, a disposição modular de elementos construtivos, a síntese das formas, a tipografia sem serifa, a predileção pelas cores primárias, o equilíbrio e a pregnância visual (KOPP, 2009).

Nos anos 1950 e 1960, o projeto de identidade visual se estabelece no contexto brasileiro. Destacaram-se os mestres Alexandre Wollner, Aloisio Magalhães, Ruben Martins, e os sócios João Carlos Cauduro e Ludovico Martino, entre outros, na região sudeste. No sul do país, importa mencionar também a atuação de Norberto Bozzetti ${ }^{8}$. Aquele período foi assinalado por um trabalho de qualidade elevada, em conjunto com o esforço de afirmação da própria identidade profissional do designer. 0 aprofundamento das questões do planejamento de marcas refletiu-se em uma produção radicalmente nova. Tratava-se de signos com alta densidade de informação no mínimo de espaço, que aliavam concisão e simplicidade em um grau de elaboração estética que transcendeu o pioneirismo: o projeto de identidade visual passou a ser compreendido como um sistema de aplicações coordenadas (STOLARSKI, 2008).

Ressalta-se o vínculo daqueles designers com o modernismo europeu e a ordem social, política e econômica, vigente no cenário nacional. O Brasil, durante o período de industrialização, passava por uma transição, na qual havia a necessidade da afirmação de uma 'unidade nacional' através da valorização de nossas fontes históricas, étnicas e culturais. Isso significava que a configuração de nossa cultura material deveria ser elaborada segundo os cânones do modernismo ${ }^{9}$, atendendo as exigências da reprodução das condições sociais. Portanto, o designer deveria atuar ao lado e a favor dos processos produtivos e seus meios, dentro da lógica capitalista requisitada pela modernização do Estado nacional (NIEMEYER, 2007).

No compasso das políticas nacionalistas e desenvolvimentistas de governos embalados por slogans como cinquenta anos em cinco ${ }^{10}$, Cardoso (2008, p. 178) sublinha que "o design brasileiro se viu levado a gerar soluções à altura dos grandes desafios sociais e culturais da época". Conforme o autor, os profissionais buscavam por formas gerais e supostamente universais, de preferência redutíveis a módulos simples e abstratos que pudessem ser eternamente recompostos de acordo com necessidades funcionais. Os designers da segunda fase modernista se viram divididos entre nacionalismo e internacionalismo, entre tradição artesanal e progresso industrial.

\subsection{Do produto ao gráfico, uma parceria em design}

Nesse questionamento, sobre como o design tem lidado com a contradição entre a posição do Brasil como país periférico e o perfil cultural do design como uma

\footnotetext{
${ }^{8}$ Designer reconhecido por projetos de identidade visual para empresas de diversos setores ao longo de cinco décadas. Ressalta-se que o jovem Bozzetti atuou como estagiário de Bornancini e Petzold.

${ }^{9}$ Enquanto marco histórico, a ruptura se dá com a Semana de Arte Moderna, realizada em 13, 15 e 17 de fevereiro de 1922, no Teatro Municipal de São Paulo. A execução de músicas de Heitor Villa-Lobos, a leitura de obras de Manuel Bandeira e Mário de Andrade, a exposição de pinturas e esculturas de Di Cavalcanti, Anita Malfatti e Victor Brecheret configurou ali o que seria o Modernismo Brasileiro, inflamado pelos discursos de Oswald de Andrade e Graça Aranha (NIEMEYER, 2007).

${ }^{10}$ Lema do Plano de Metas do presidente Juscelino Kubitschek. A construção da nova capital, Brasília, foi a imagem mais eloquente de seu governo. O projeto de Oscar Niemeyer era a expressão em concreto de uma ideologia e concepção de poder: impactante, forte, audaz e inovadora (NIEMEYER, 2007).
} 
atividade 'de ponta' em termos tecnológicos ou 'de vanguarda' em termos estilísticos, Cardoso (2008) exemplifica com o trabalho dos designers aqui em retrospecto:

Existem casos individuais de designers no Brasil que tem conseguido realizar os seus projetos dentro de padrões tecnológicos correspondentes ao exterior e totalmente inseridos em uma linguagem internacional de design como, por exemplo Karl Heinz Bergmiller (nas décadas de 1960 e 1970) ou José Carlos Mário Bornancini (a partir da década de 1960). O escritório Bornancini e Petzold (o outro sócio é o arquiteto Nelson Ivan Petzold) é responsável por mais de duzentos projetos, em variados segmentos - desde garrafas térmicas e talheres até tratores e elevadores -, e constitui-se em caso de indiscutível sucesso, colecionando prêmios e patentes ao longo de quatro décadas. Transitando com rara desenvoltura pelo sistema corporativo, ao qual pertencem seus clientes, alguns multinacionais, a dupla gaúcha tem demonstrado que é possível fazer design no Brasil em pé de igualdade com países de tecnologia e economia mais avançadas (CARDOSO, 2008, p. 217).

Em sua análise sobre produtos desenvolvidos por Bornancini e Petzold, Curtis e Hennemann (2006) observam que o design brasileiro, para ser valorizado no país ou no exterior, precisa apresentar características próprias e certa regionalidade. Segundo as autoras, na garrafa térmica Chimarrita, destinada ao público que tem o hábito de beber chimarrão, contempla-se a cultura local e, nos talheres Camping ${ }^{11}$, o enfoque atende um público mais abrangente e universal. Nesses produtos há inovação e funcionalidade associadas à estética: o design abrange diferentes mercados, regional e universal.

Petzold (2016) acrescenta o caso dos talheres Comer Brincando: o aspecto visual nasce com o produto, quando as discussões sobre design de superfície e tópicos sobre as dimensões significativas dos artefatos ainda eram incipientes. Isto não era feito de modo arbitrário ou como mero recurso estilístico: "a Chimarrita evoca à identidade local, e o conjunto Comer Brincando foi pensado para incentivar as crianças a comer" (PETZOLD, 2016). Sobre os talheres, Fidelis (2014, p. 7) pontua: "além de serem relevantes pela excelência de seu design, tiveram uma forte presença no imaginário social de um determinado período". Por conseguinte, verifica-se que os projetos se valem das prerrogativas funcionalistas e, por vezes, as concilia com signos visuais, conforme a figura 1:
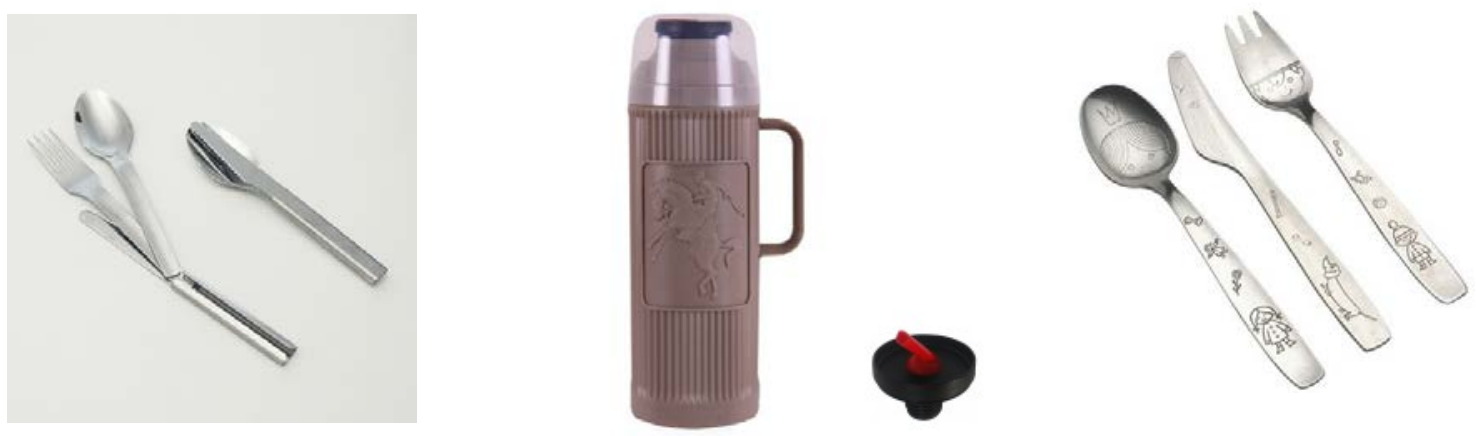

Figura 1 - Da esquerda para a direita: talheres Camping, térmica Chimarrita (com a rolha Dupla Ação) e talheres Comer Brincando. Fonte: arquivo Petzold (2016).

11 O projeto dos talheres Camping, desenvolvido para a Zivi-Hércules, em 1976, foi premiado no Museu de Arte Moderna de Nova York, MOMA. 
Ao relembrar a época de estudante, Petzold (2016) salienta que não teve acesso ao conhecimento formal em design gráfico. O curso de arquitetura da UFRGS já tinha o foco no projeto de edificações, ao contrário do curso da Universidade de São Paulo - USP, que incluía uma sequência de disciplinas de desenho industrial e comunicação visual no currículo (NIEMEYER, 2007). Quando estava no segundo ano da faculdade, começou a trabalhar no escritório de arquitetura Almeida, Turquenitch \& Cia. Ltda. O projetista afirma que gostava de fazer tudo o que os colegas não gostavam: o detalhamento. Embora a empresa não desenvolvesse projetos de comunicação visual, Petzold era o responsável pela elaboração do material de expediente, sendo esta a sua vivência inicial na área gráfica. Após sua formatura, se tornou sócio do escritório. Mais tarde, o projetista deixaria o escritório de arquitetura ao receber o convite de Bornancini para lecionar na Escola de Engenharia ${ }^{12}$.

Em 1962, Petzold iniciou a docência na disciplina de Desenho Técnico dos cursos de Arquitetura e Engenharias e, no ano de 1970, atuou como vice-diretor da Faculdade de Arquitetura (CURTIS; COSSIO, 2015). O professor recorda os exercícios de letreiro em sua disciplina:

\begin{abstract}
Para sensibilizar os alunos, eu levava exemplos, e o que mais gostava de exibir era um logotipo da Volkswagem. Apontava então os erros cometidos desde a separação das letras (kerning), suas proporções e alinhamento. Era o exemplo de uma marca poderosa mal representada. Ensinávamos "letreiro" a partir da norma brasileira, de cujas bases o aluno de arquitetura de alguma forma já se apropriara, o que não era o caso de alunos de outros cursos. Eram três ou quatro aulas de letreiro, desde a proporção da letra ao seu espaçamento. Dizia aos alunos que geralmente as pessoas não se dão conta do que o desenho significa (PETZOLD, 2016).
\end{abstract}

Portanto, verifica-se a sensibilização para as questões da comunicação visual desde o início da carreira, bem como no exercício da docência. A seguir, o portfolio em design gráfico da parceria passa a ser de interesse para o estudo.

\title{
2.3 Projetos gráficos desenvolvidos por Bornancini e Petzold
}

Com o reconhecimento por seu trabalho a partir dos produtos que desenvolviam, em muitas vezes, eram também contratados para realizar os projetos gráficos para as respectivas indústrias ${ }^{13}$. Para exemplificar o caso típico de design de produto que se desdobra em design gráfico, fato recorrente ao longo de sua trajetória, vale mencionar a fabricante da Chimarrita. O caso Termolar consiste em uma linha de garrafas térmicas de sucesso, pois a maioria dos modelos e a identidade visual da empresa seguem inalterados até hoje.

\footnotetext{
12 Petzold passou a indicar alunos para trabalhar no escritório: João C. Mena Barreto, Helio Greven, Ério Gomes de Oliveira, Edgar Sirangelo do Vale, Elvan Silva, Pedro Simch, entre outros.

${ }^{13}$ As empresas para as quais projetaram identidades visuais incluíram Arcil, Arcon, Braseletron, Cedro, Ferrisan, Intral, Jackwal, Memphis, Metalúrgica Becker, Steigleder, Taurus, Termolar, Tochetto, Wallig, e Zivi-Hércules. Entre as embalagens, destacaram-se a do conjunto Bar Set, e para faca da marca Mundial. Na elaboração de catálogos, um exemplo é o trabalho para a Pincéis Oderich, com apoio do arquiteto Ronald Spiecker. Já para o setor público, sem vínculo com projeto de produto, foram as marcas da Companhia Riograndense de Saneamento - CORSAN e da Secretaria Municipal de Obras e Viação SMOV. Os estudos para a identidade visual da Cia. Carris, de transporte coletivo, foram iniciados, porém o projeto esbarrou na burocracia do município. Além disso, participaram de um concurso para a nova marca da cia. aérea Varig.
} 
Petzold (2016) relembra que projetaram a marca a partir de uma associação entre o produto e a letra ' $t$ '. Ao comentar esta solução, o designer pondera sobre a dificuldade em desenhar um símbolo a partir de um produto: se a ligação for muito forte, amarra-se o símbolo ao produto desenvolvido, o que pode necessitar ser repensado em uma eventual mudança na empresa. Além disso, quando a marca explicita muito determinado objeto, ela corre o risco de ficar datada, pois o objeto se transforma e evolui. Porém, conta que na Termolar tinham as condições, uma vez que a forma do objeto lembrava a letra ' $\mathrm{t}$ '. Inicialmente, consideraram o símbolo demasiado simplista sem acabamento, e a solução foi acrescentar uma moldura. Funcionava como um selo na embalagem, com o objetivo de indicar qualidade. 0 departamento de marketing também solicitou uma versão da marca que lembrasse o esporte, o verão e o inverno (figura 2):

\section{[0] TERMOLAR}
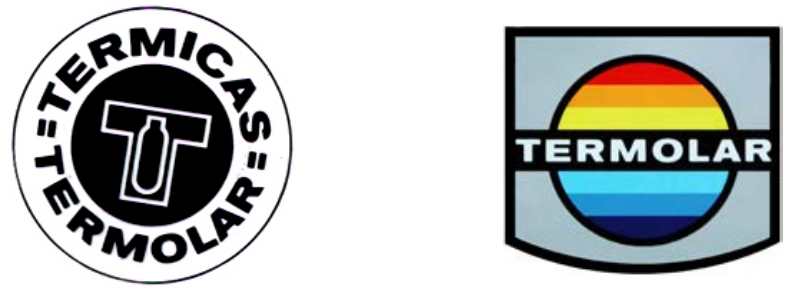

Figura 2 - Identidade visual Termolar: versão padrão horizontal, selo e versão esportiva. Fonte: arquivo Petzold (2016).

Ao observarmos a linguagem visual das marcas idealizadas por Bornancini e Petzold, percebe-se a influência de raiz modernista, nos parâmetros preconizados por Cardoso (2008) e Kopp (2009). Nos símbolos e logotipos da figura 3, predominam características como a geometria, a síntese das formas, a repetição de elementos, o alto contraste, o equilíbrio e a pregnância visual, resultando em uma configuração formal econômica.

\section{maguefa}

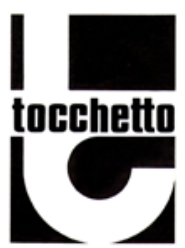

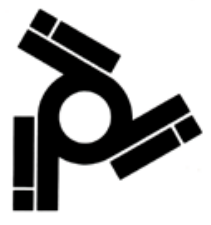

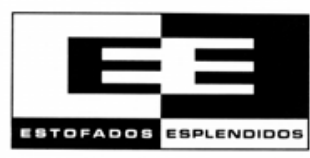

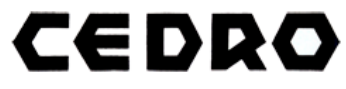

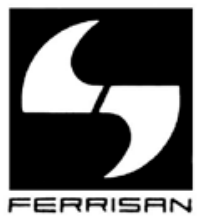

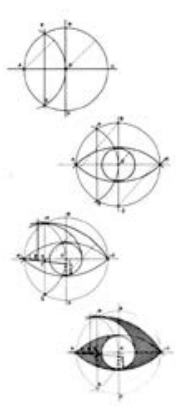

aICIL

Figura 3 - Identidades visuais Grupo Maguefa (do setor imobiliário), Distrito Industrial Gravataí, Cedro, Tochetto, Estofados Esplendidos e Ferramentas Ferrisan. À direita, construção do símbolo e marca Arcil Condicionadores de Ar.

Fonte: arquivo Petzold (2016).

A marca para a Metalúrgica Wallig foi uma das primeiras desenvolvidas por Bornancini, antes da sociedade com Petzold, e já incorporava as prerrogativas estéticas do modernismo, com um rebatimento do sinal gráfico check, que indica aprovação. Assim como a Wallig, os símbolos para a Hércules e Móveis Todeschini são fonogramas 
compostos por formas básicas e, juntamente com o logotipo, estabelecem um jogo entre positivo e negativo, como pode ser visto na figura 4:
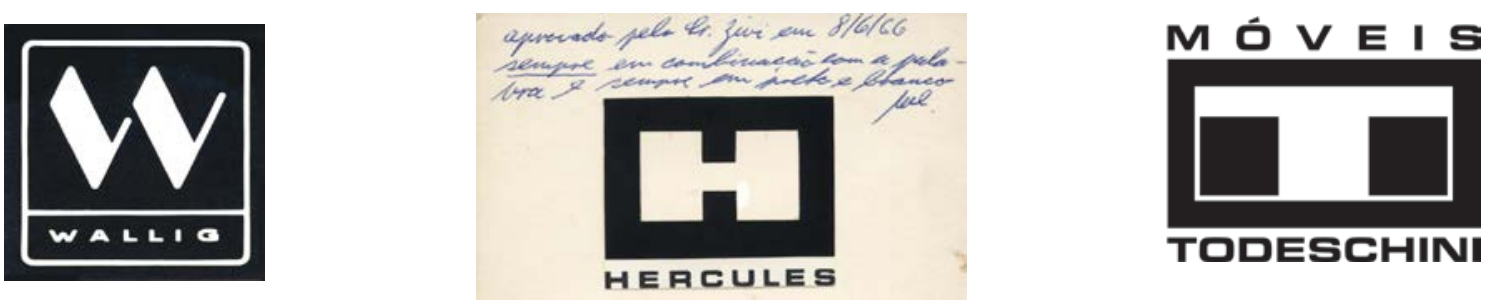

Figura 4 - Identidade visual Metalúrgica Wallig, e versão aprovada para a Hércules. À direita, marca para a Móveis Todeschini.

Fonte: arquivo Petzold (2016).

Em suas palestras para estudantes de graduação, Petzold (2016) aponta o respeito à história da organização contratante como diretriz para o desenvolvimento de projeto: "os jovens designers devem ter cuidado quando iniciam em uma empresa, e refletir sobre o que realmente se faz necessário alterar. Cansamos de ver marcas que eram refeitas quando não precisavam ou não deveriam ser redesenhadas". No entanto, a marca da Metalúrgica Jackwal já não acompanhava a linguagem visual da época.

Os designers propuseram uma nova versão, de maior pregnância visual. Em seguida, repensaram sua primeira solução, de modo a conferir destaque para o nome. Mais tarde, uma empresa de marketing fundiu o símbolo com o logotipo, sendo esta a versão utilizada atualmente (figura 5). Sobre esse recurso, Petzold (2016) recomenda cautela ao substituir o caractere por símbolo gráfico, pois pode-se criar um ruído visual, o que prejudica tanto o nome quanto a marca.
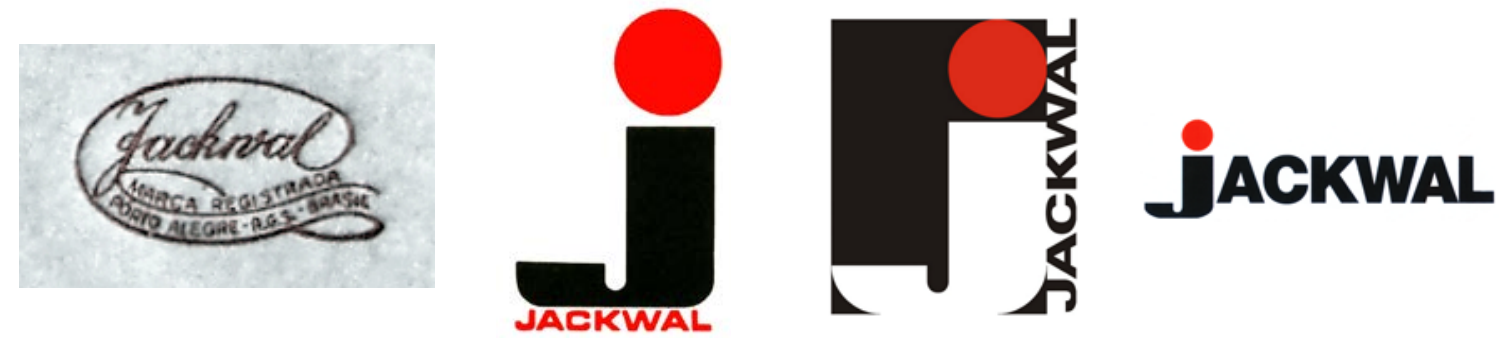

Figura 5 - Identidade visual Metalúrgica Jackwal: à esquerda, a marca anterior, ao centro, o projeto original de Bornancini e Petzold e versão redesenhada por ambos e, à direita, a versão atual. Fonte: arquivo Petzold (2016).

Ainda sobre o tratamento do nome, Petzold (2016) explica que este é um item sensível no projeto de identidade visual:

Se a marca não está sempre na mídia deve ser ainda melhor construída, pois a propaganda massiva termina 'embutindo' na cabeça das pessoas aquela mensagem, independente de ser boa ou ruim. Quase todos os nossos clientes eram de médio ou pequeno porte. Assim tínhamos que ter um cuidado especial com o tratamento do nome, além do desenho do símbolo. Então, tínhamos por princípio conferir destaque ao nome. As marcas que 
atualmente funcionam apenas com o símbolo, dispensando o logotipo, são as que realizam altos investimentos em propaganda (PETZOLD, 2016).

A propósito do processo de criação, Petzold (2016) ressalta a importância da etapa de geração de alternativas. Para o projetista, o diretor da instituição usualmente não entende ou não tem olho para enxergar, e aceita o que os profissionais estão dizendo. Isso demonstra a responsabilidade dos designers nesse sentido. Por isso, deve-se fazer uma análise muito profunda do que se está propondo. 0 designer tem que ter a humildade de conseguir criticar a sua solução, questionar se ela é realmente a mais adequada. Como consequência, o projeto é aperfeiçoado (PETZOLD, 2016). Os estudos da figura 6 ilustram a etapa de geração de alternativas para a Hércules e para a Metalúrgica Becker.

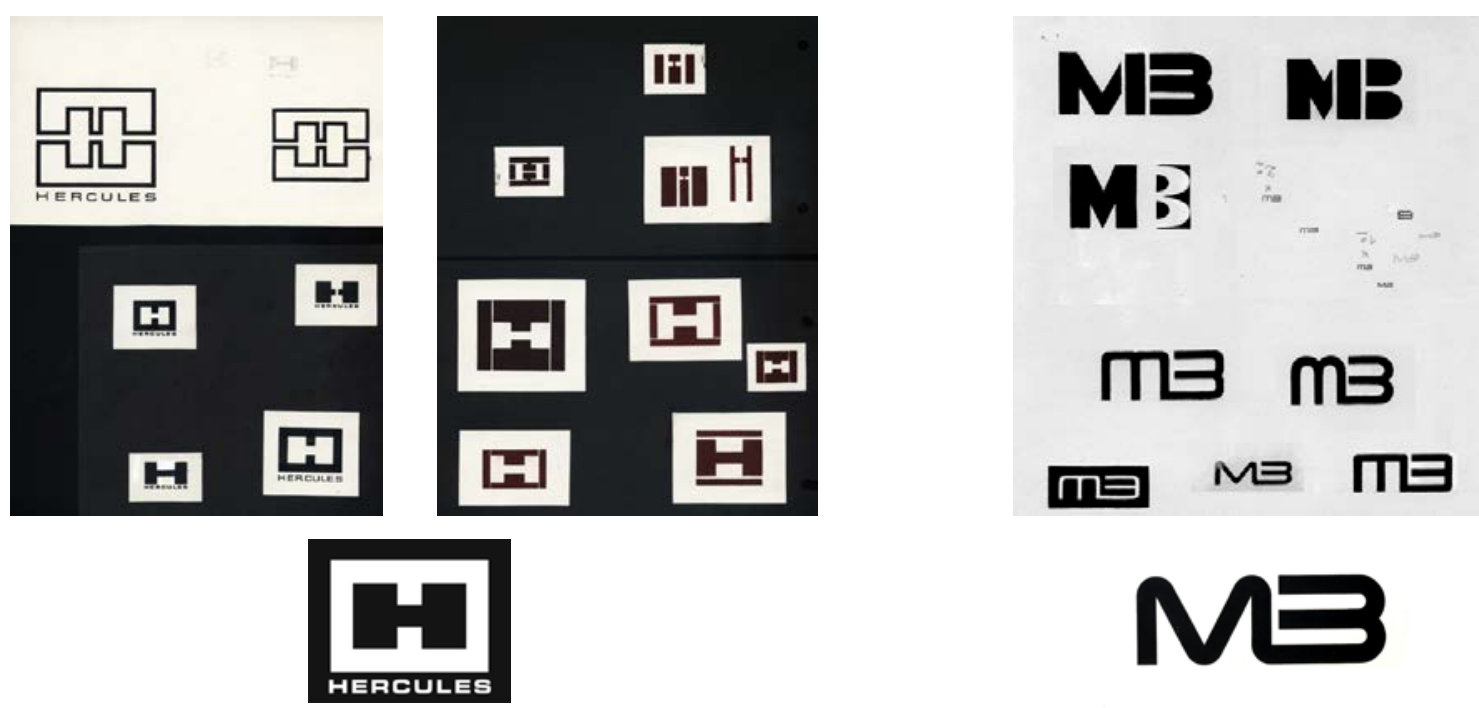

Figura 6 - Acima, a geração de alternativas e, embaixo, o resultado para a Hércules, e para a Metalúrgica Becker.

Fonte: arquivo Petzold (2016).

Já no âmbito do projeto de embalagem, vale mencionar os casos Bar Set da Hércules, e a faca Mundial, da Zivi. Petzold (2016) salienta que a impressão colorida ainda estava começando: a primeira embalagem colorida que realizaram foi feita com clichês de zinco, em duas cores, chapada, na antiga Typographia Mercantil. Tratava-se de uma composição que destacava os objetos e sua utilização. Ainda não eram disponibilizados recursos para embalagens destinadas ao auto-serviço, tipo 'blister' ou 'skin' ou com 'janela', conforme requisitadas pelos clientes. Assim, foi desenvolvido um tipo de embalagem para facas, internamente chamada de janelinha, que foi utilizada por muitos anos.

Para a faca da Zivi, idealizaram um invólucro que mostrasse o utensílio. Petzold (2016) explica que planejaram uma embalagem composta de três partes: uma base conformada em papelão duplex, uma lâmina de policloreto de vinil - PVC e uma capa colada na base, fixando assim a janela de PVC. Uma lingueta ficava aberta para colocar a faca e, depois, era fechada. Porém, na época, a gráfica não tinha condições de produzir aquele modelo complexo. Então, a dupla projetou a máquina para fazer a embalagem. Tinham algum entendimento de estampagem, que aplicaram na ocasião. Nesse aspecto, indicam a possibilidade de incorporar técnicas de outros segmentos em um determinado projeto. Os designers ensinaram os operários na fábrica como utilizar 
a máquina para produzir as embalagens. Petzold (2016) conta que várias daquelas máquinas foram construídas posteriormente, em versões mais elaboradas, com o uso de comandos hidráulicos. As embalagens e um desenho esquemático daquela máquina podem ser vistos na figura 7 :
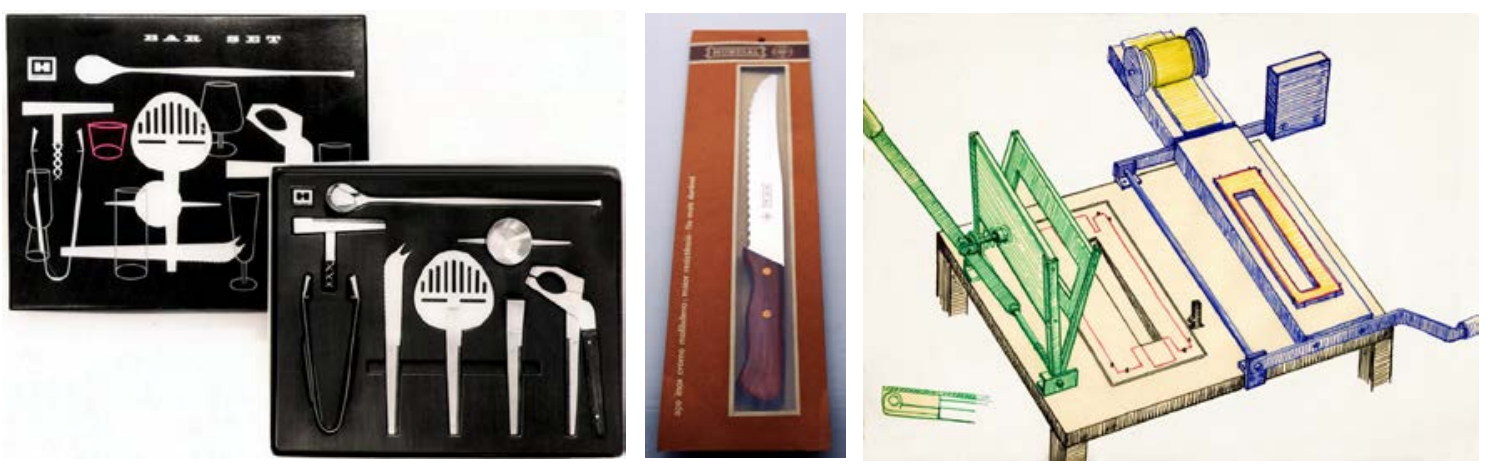

Figura 7 - Embalagem para o conjunto Bar Set, da Hércules. Embalagem auto-serviço para a faca da linha Mundial, da Zivi e desenho da máquina que a produzia.

Fonte: arquivo Petzold (2016).

No que se refere a trabalhos destinados ao setor público e, nestas ocasiões, excepcionalmente sem vínculo com o desenvolvimento de produto, Bornancini e Petzold foram os responsáveis pelos projetos de identidade visual para a Secretaria Municipal de Obras e Viação - SMOV, de Porto Alegre, e Companhia Riograndense de Saneamento - CORSAN. Em reportagem do Informativo Interno da CORSAN, é mencionado que a marca foi projetada em 1965, logo com o planejamento para a formação da empresa. Acrescenta-se que os designers buscaram se familiarizar com o trabalho na área de saneamento para realizar o projeto de identidade visual.

Em entrevista para aquela matéria, Bornancini lembra que, na época de realização do projeto "estavam na moda os símbolos abstratos [...] nós achávamos que o símbolo deveria estar ligado à atividade da empresa, e que havia necessidade de uma identificação com o nome porque se tratava de impor a marca". Outro requisito de projeto era a facilidade de reprodução do símbolo, uma vez que seria repetido em vários lugares, e em diversos tamanhos e materiais. Por isso, o designer justifica que tiveram a preocupação de usar as linhas retas e indicar as medidas das letras e dos espaçamentos, para que não se perdesse a uniformidade na reprodução ao longo do tempo, conforme a figura 8.

\section{SMINO}

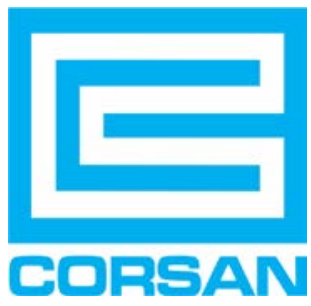

Figura 8 - Identidades visuais para o setor público: SMOV e CORSAN.

Fonte: arquivo Petzold (2016).

De acordo com o texto de Bornancini na apresentação do Manual de Identidade Visual, o símbolo representa a letra ' $c$ ' de CORSAN, com um desenho que 
caracteriza um decantador. As partes cheias representam as paredes (chicanas) formando a letra ' $c$ ' com os vazios resultantes que representam a parte com água do decantador. É possível estabelecer um nexo entre este caso em design gráfico e o que ressaltou Fidelis (2014) anteriormente, sobre o trabalho da parceria em design de produto: pela excelência do seu projeto e capilaridade em âmbito estadual, a marca da CORSAN tem forte presença no imaginário da população gaúcha há cinco décadas, e permanece inalterada até os dias atuais.

\section{CONCLUSÃO}

A familiaridade com as coisas vai auxiliar a desenvolver o projeto, seja de produto ou no design gráfico. Tem que ter vivência, participar dos processos. Aí podemos fazer uma relação com a marca da CORSAN que surge da ideia do tratamento da água. Tem que ver o tratamento da água. Sem sair do escritório não se tem esse entendimento. - Nelson Ivan Petzold, 2016.

Em uma síntese sobre a evolução do papel do designer, De Moraes (2008) afirma que, no início do século $X X$, o profissional era visto como o responsável pelo projeto de um produto isolado ou de uma imagem gráfica específica, interferindo pouco nos aspectos produtivos e parcialmente no ciclo de vida de um produto. Nos meados do século, esse mesmo profissional começou a projetar sistemas de produtos e sistemas gráfico-visuais, passando a considerar o produto não mais de modo isolado na produção, mas como parte integrante de um todo que incluía fatores produtivos, de uso, ambientais e de mercado.

Com efeito, Bornancini e Petzold trabalharam no processo de industrialização, a partir dos anos 1960, época em que o projeto de identidade visual se estabelece no país. Ao transitar com desenvoltura do projeto de produto ao gráfico para diversos setores, os designers anteciparam a atuação de viés generalista, quando já havia agências de propaganda no sul, porém uma escassez de profissionais especializados em comunicação visual ${ }^{14}$. O perfil investigativo, capaz de articular variados saberes na inovação de produtos e processos, somado às vivências no ensino de desenho técnico, são fatores que corroboram a genialidade projetual de Bornancini e Petzold, também em design gráfico. Espera-se que essa análise sobre o portfolio da dupla acrescente tanto para o estudo sobre história do design no Brasil quanto para o ensino e desenvolvimento de projeto, com a elaboração dos princípios listados no quadro 1:

Quadro 1 - Princípios para o ensino e desenvolvimento de projeto com base no portfolio de design gráfico de Bornancini e Petzold. Fonte: elaborado pelo autor.

a) Diálogo entre regionalidade e linguagem universal;

b) Concepção racionalista como estratégia para viabilizar o projeto, especialmente para pequenas e médias empresas;

c) Respeito ao histórico das instituições e bom senso em casos de redesign;

d) Ênfase na geração de alternativas e análise crítica da proposta;

e) Imersão: curiosidade, vivência e familiaridade.

14 Petzold (2016) relata que foram responsáveis por supervisionar o planejamento da comunicação e elaboração de anúncios para marcas e produtos que projetaram previamente como, por exemplo, o material promocional para a Móveis Todeschini (CURTIS; COSSIO, 2015) e para a Metalúrgica Wallig (FIDELIS, 2014). 
Como estudos futuros, além de aprofundar os fatores elencados acima, podese refletir sobre as metodologias que se estabelecem na autoria comum entre produtos, identidades visuais e peças gráficas correspondentes. Além disso, torna-se relevante para a história da atividade a ação interdisciplinar entre design e museologia, e a análise sobre a dimensão significativa de ícones do design gráfico e de produto para a inserção de uma cultura local de projeto, bem como os seus influxos na memória e no imaginário social.

\section{REFERÊNCIAS}

ALBERTI, Verena. Manual de História Oral. Rio de Janeiro: Ed. FGV, 2007.

BORNANCINI, José Carlos Mário. Manual de Identidade Visual CORSAN. Disponível em <http://www.corsan.com.br> Acesso em 28 abr. 2016.

CARDOSO, Rafael. Uma introdução à história do design. São Paulo: Blücher, 2008.

CURTIS, Maria do Carmo; COSSIO, Gustavo. El proyecto de Bornancini e Petzold: un estudio de innovación de producto para Todeschini. In: MONDRAGÓN, H.; MEJíA, C. (Org.) Sudamerica Moderna: objetos edificios territorios. Santiago: ARQ, 2015.

CURTIS, Maria do Carmo. Funcionalismo: referência histórica para o design social. In: 9o Congresso Brasileiro de Pesquisa e Desenvolvimento em Design - P\&D Design.

Anais... São Paulo: UAM, 2010.

CURTIS, Maria do Carmo; HENNEMANN, Helena. Bornancini - Uma Trajetória no Design de Produto. Estudos em Design, v. 14, n. 2, 2006.

DE MORAES, Dijon. Limites do design. São Paulo: Studio Nobel, 2008.

ELLWANGER, Daniele; LIMA, Guilherme da Cunha. Resgatando uma Parceria: Bornancini, Petzold e Müller. In: 8o Congresso Brasileiro de Pesquisa e Desenvolvimento em Design - P\&D Design. Anais... São Paulo: Senac, 2008.

FIDELIS, Gaudêncio. Design como prioridade museológica. In: Fogão Wallig. ZAVADIL, Ana (Org.) Porto Alegre: Museu de Arte do Rio Grade do Sul, 2014.

GRUSZYNSKI, Ana. Design Gráfico: do invisível ao ilegível. São Paulo: Rosari, 2008. INFORMATIVO INTERNO DA CORSAN. Logotipo marca presença no RS. 1983. KOPP, Rudinei. Design Gráfico Cambiante. Santa Cruz do Sul: EDUNISC, 2009. LEON, Ethel. Design brasileiro quem fez, quem faz. Rio de Janeiro: Ed. Senac, 2005. LUPTON, Ellen; MILLER, J. Abbot. O ABC da Bauhaus. São Paulo: Cosac Naify, 2009. NIEMEYER, Lucy. Design no Brasil: origens e instalação. Rio de Janeiro: 2AB, 2007. PETZOLD, Nelson Ivan. Entrevista ao autor sobre a atuação em design gráfico. 2016. SOUZA, Pedro L. P. de. Notas para uma história do design. Rio de Janeiro: 2AB, 2008. STOLARSKI, André. A identidade visual toma corpo. In: MELO, Chico Homem de (Org.) O design gráfico brasileiro: anos 60. São Paulo: Cosac Naify, 2008. 